\title{
Research on the Influence of Recommended Sources on the Adoption Intention in Online Shopping Environment
}

\author{
Haiquan Chen, Huan Wang, Li Liu \\ School of Management, Jinan University, Guangzhou, China \\ Email: ArielWongh@163.com
}

How to cite this paper: Chen, H.Q., Wang, H. and Liu, L. (2017) Research on the Influence of Recommended Sources on the Adoption Intention in Online Shopping Environment. Journal of Service Science and Management, 10, 413-424. https://doi.org/10.4236/jssm.2017.105033

Received: September 22, 2017

Accepted: October 21, 2017

Published: October 24, 2017

Copyright ( 92017 by authors and Scientific Research Publishing Inc. This work is licensed under the Creative Commons Attribution International License (CC BY 4.0).

http://creativecommons.org/licenses/by/4.0/

\begin{abstract}
The development of shopping website allows consumers to enjoy the convenience brought by the Internet, but too much commodity information makes consumers have no choice, thus the personalized recommendation come into being. A good personalized recommendation system can help consumers reduce the cost of information search and make quick purchase decisions. Correspondingly inappropriate recommended time nodes and recommendation information will cause consumer dissatisfaction, affecting the consumer's shopping experience. This paper focuses on the impact of the recommended information sources in the personalized recommendation service on the adoption of consumer information. It also verifies the mediating and regulatory effects of perceived usefulness and cognitive complexity on the effect of recommended information on the adoption intention.
\end{abstract}

\section{Keywords}

Recommended Information Sources, Perceived Usefulness, Cognitive Complexity, Adoption Intentions

\section{Introduction}

Nowadays Internet economy is no stranger, new economic patterns continue to be derived and e-commerce shows explosive growth. Something like Crossborder Electronic Commerce and $\mathrm{O} 2 \mathrm{O}$ are gradually integrated into the lives of ordinary consumers. According to China Competition Information, China's online retail sales in 2016 was 5.1 trillion yuan, increased $26 \%$. The annual online retail sales accounted for $12 \%$ of total retail sales of social consumer goods, and Double Eleven Carnival has set a new record in November, which accounted for 
15.3\%. Consumers' daily Internet browsing behavior generates a large amount of data, and enterprises are increasingly attaching importance to it. "Age of Big date" has promoted the rapid development of big data marketing, and the personalized recommender system came into being, which is an effective solution to solve consumers' information problems. It provides more convenient online shopping service for consumers.

The Personalized Recommendation System recommends a series of merchandise list to the consumers. For the end consumers, they get access to the specific product information. But some questions like whether the user will accept the recommended information and purchase the products, the reason why the users accept the recommended information and what factors will affect the user to accept the recommended information still need further exploration. Based on above analysis, this paper will focus on the online shopping environment, and explore the internal psychological formation mechanism of individual adoption intention of the proposed commodity information in order to contribute to the theory and practice.

\section{Theoretical Basis and Research Hypothesis}

\subsection{Recommended Information Sources and Adoption Intention}

The recommended information sources refers to where the information comes from and what is the basis (Senecal \& Nantel, 2004) [1]. The consumer's activity on the shopping website is an interactive process of the consumer subject and the information recommendation system. For consumers, the direct contact with the E-commerce site is the recommended product interface, and existing with the commodity information is recommended explanation, which is the recommended information sources. Goodman and Griffin (2013) [2] believes that the recommended information sources can be divided into recommendations based on personal preference and recommendations based on related customers, mainly for the individual decision-making process to give reference, edge clues.

Information adoption is a result of the individual's initial analysis and processing of information (Christy \& Matthew, 2008) [3], and is to find information consistent with their own needs in the process of processing, then make the decision to adopt, which is a decision (Song Xueyan, 2010) [4]. In the field of E-commerce, the adoption intention is divided into two steps: The first step is that the recommended system pushes information to consumers through calculation and consumers according to their own needs and preferences to filter the recommended information; The second step is that after consumers have seen the detailed push information, they will decide whether to accept the recommendation and add it to the collection, or whether to take the next step, which is purchase decision.

In the field of recommendation adoption, the recipients can perceive a similarity to the recommender, including the preference of the brand of the commodity or the preference of function, or the individual characteristics. Gilly 
(1998) [5] found that the similarity of information recipients and communicators will have an impact on consumers' final purchase decisions in the research of Word-of-mouth marketing. Faraji-Rad, Samuelsen and Warlop (2015) [6] summarizes previous studies of the process interpretation of the positive effects of sources similarity on persuasion, an explanation is that the similar individuals are considered to have the same preferences, making their proposals more convincing, Another explanation is to keep this connection between similar people and follow their advice. Jiang (2010) [7] found that consumers were more likely to express their preferences and to adopt their suggestions when they found consumers with the same preferences. Thus, we speculate that the recommendation based on the associated customer can give consumers a sense of certainty, and they are more likely to receive the recommendations made by similar customers. Therefore, this paper puts forward the hypothesis:

$\mathrm{H1}$ : The recommended information sources affects consumers' adoption intention positively.

H1A: Whether it is based on personal preference or based on the relevant customer referral, the recommended information sources is positively affecting consumers to adopt the intention;

H1B: compared with recommendations based on personal preferences, the recommended information based on relevant customers are more likely to be adopted by consumers.

\subsection{Perceived Usefulness}

The consumer's perception of the recommended information is whether the recommended commodity information satisfies the individual's needs or preferences, whether the quality of the recommended product is guaranteed, or whether it is useful for the individuals.

Sinha and Sweringen (2001) [8] pointed out that when recommending products to consumers on e-commerce shopping website, the recommended explanation was the sources of recommendation, which made consumers perceived that the recommendation system of the shopping website was transparent and would not have obvious aversion to it, which would positively affects the usefulness perception of the recommended commodity information.

Scholars such as Francisco and Irene (2015) [9] have integrated TAM Model, TPB Theory and Trust Mechanism, they found that consumers' trust and perceived usefulness will significantly influence the adoption intention.

Based on TAM Model, Yang Yiwong, Wang Yi and Sun Guohui (2016) [10] cited perceived usefulness and perceived ease of use to study the consumer's recommendation adoption intention, they found that mediator effect of perceived usefulness is obvious, while the impact of perceived ease of use is not obvious. In the process of dealing information, the perceived usefulness can provide basis for consumers' purchase decisions and reduce the uncertainty of recommending products. Therefore, this paper puts forward the hypothesis: 
H2: Perceived usefulness plays a mediating effect between the recommended information sources and adoption intention.

\subsection{Cognitive Complexity}

Cognitive complexity refers to the ability of individuals to describe everything from different perspectives, including abstract viewpoints, concepts (Suedfeld, 1992) [11]. In general, individuals with high cognitive complexity can make their own judgments about things more comprehensively than those with low cognitive complexity, and they have a strong ability to integrate. While Novis Deutsch (2015) [12] holds the view that the complexity of the individual's self-perception affects his or her acceptance of other people's suggestions.

Van Seggelen Damen (2013) [13] found that the higher the cognitive complexity of an individual, the less likely it is for them to accept the opinion of others, because the individuals with high cognitive complexity mean that his cognitive process is accomplished through the processing of the information itself. With a higher cognitive ability, they also tend to be self-thinking in the process of information processing, and they always reference to their own ideas and cognitions, but less reference to other people's suggestions. While the individuals with low cognitive complexity are the opposite.

Bunan and Du xiufang (2015) [14] studied the impact of social cognitive complexity on the adoption of recommendations by using the classic paradigm of "decision makers-recommendations". They found that the difference of cognitive complexity have a different impact on the degree of acceptance of the proposed trial, as individuals with low cognitive complexity are more likely to accept others' suggestions as a reference for their own decisions. As a result, we speculate that the higher the level of cognitive complexity, the greater the independence of the consumer is, the more likely it is for them to accept recommendations based on personal preference rather than accepting referrals from associated customers. Therefore, this paper puts forward the hypothesis:

H3: The cognitive complexity plays a moderating role between the recommendation information sources and the information adoption intention of individuals.

H3A: For individuals with high cognitive complexity, there is a higher adoption intention for information based on the individual preference than the referral information based on the associated customers;

H3B: For individuals with low cognitive complexity, there is a higher adoption intention for information based on the relevant customers than the recommended information based on the individual preference.

The model structure of this paper is shown in Figure 1:

\section{Research Design and Data Analysis}

\subsection{Research Design}

The purpose of this paper is to study the effect of the recommended information 


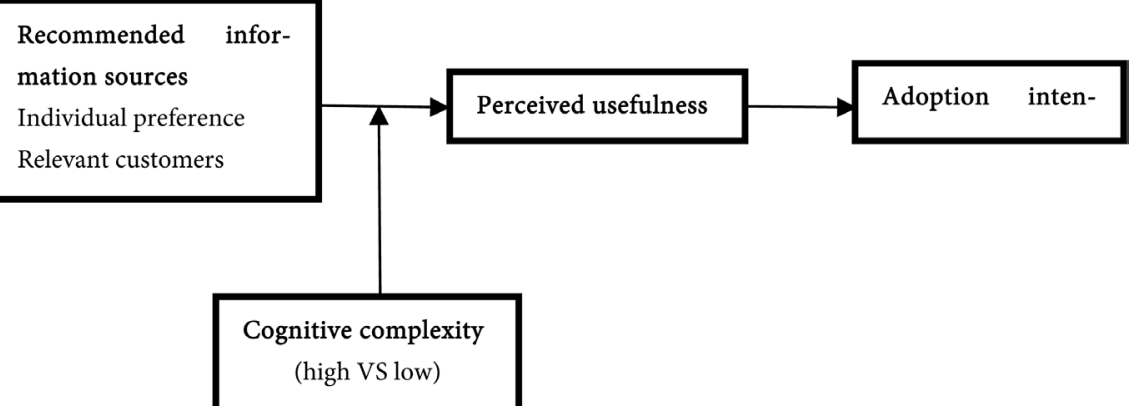

Figure 1. Impact mechanism model of recommended information.

sources on consumers' adoption intention, and to verify the mediating effect of perceived usefulness between the recommended information sources and the individual adoption intention, the moderating effect of cognitive complexity between the recommended information sources and the individual adoption intention. Therefore, this paper implements two experiments to verify the hypothetical relationship between these variables. As is shown in Table 1.

\subsection{Experiment One: The Relation of Recommended Information Sources, Perceived Usefulness and Individual Adoption Intention}

Experiment one is to test the effect of the recommendation information sources on the individual's adoption intention (H1) and the mediating effect of perceived usefulness (H2), using Single factor group experiment design (Recommended information sources: Individual preference VS relevant customers), dependent variable is consumer information adoption intention. In addition, we also add a control group to provide product recommendations that do not have a recommended information sources. The experiment was conducted in the class by questionnaires, and the total questionnaires are 125, the final recovery questionnaires are 114. After the questionnaire statistics, according to the principle of the invalid questionnaire (regular answer, no online purchase experience, miss above three questions), eliminating 6 questionnaires, we got 108 final effective questionnaires, including $55.2 \%$ of male, $44.8 \%$ of female, and the average age was 20.3 years, the average access time for Internet (including mobile) was 3.6 hours.

From Table 2 and Table 3, there is a significant difference in adoption intention between individual preference, associated customers and No referral information $(\mathrm{M}$ personal preference $=3.468, \mathrm{SD}=0.617 \mathrm{vs}$. $\mathrm{M}$ associated customers $=$ $3.775, \mathrm{SD}=0.662$ vs. $\mathrm{M}$ none $=3.274, \mathrm{SD}=0.315, \mathrm{~F}=6.745, \mathrm{df}=107, \mathrm{p}=0.002)$. Therefore, H1, H1A and H1B have been validated, that is, the recommended information sources have a significant positive effect on consumers' adoption intention, and the recommendation information based on the associated customers has higher adoption intention than recommended information based on personal preference and recommended information with no recommendation sources. 
Table 1. The research design.

\begin{tabular}{ccc}
\hline Experiment & Experimental purpose & Experimental design \\
\hline One & Test the hypothesis H1, H2 & $\begin{array}{c}\text { Recommended information sources: Individual } \\
\text { preference VS Relevant customers VS None }\end{array}$ \\
\multirow{2}{*}{ Two } & Test the hypothesis H1, & Cognitive complexity : high VS low \\
\hline
\end{tabular}

Table 2. Mean comparison of main effects.

\begin{tabular}{|c|c|c|c|c|c|c|}
\hline & \multirow{2}{*}{$\mathrm{N}$} & \multirow{2}{*}{ Mean } & \multirow{2}{*}{$\begin{array}{c}\text { Std. } \\
\text { Deviation }\end{array}$} & \multirow{2}{*}{$\begin{array}{l}\text { Std. } \\
\text { Error }\end{array}$} & \multicolumn{2}{|c|}{ 95\% Confidence Interval for Mean } \\
\hline & & & & & Lower Bound & Upper Bound \\
\hline Individual preference & 37 & 3.486 & 0.617 & 0.101 & 3.281 & 3.692 \\
\hline Relevant customers & 43 & 3.775 & 0.662 & 0.101 & 3.572 & 3.979 \\
\hline $\begin{array}{l}\text { No recommended } \\
\text { information sources }\end{array}$ & 28 & 3.274 & 0.315 & 0.060 & 3.152 & 3.396 \\
\hline Total & 108 & 3.509 & 0.351 & 0.034 & 3.442 & 3.576 \\
\hline
\end{tabular}

Table 3. One-way ANOVA.

\begin{tabular}{cccccc}
\hline & sum of squares & df & Mean Square & F & Significant \\
\hline Between groups & 4.464 & 2 & 2.232 & 6.745 & .002 \\
Within groups & 34.749 & 105 & 0.331 & & \\
Total & 39.213 & 107 & & & \\
\hline
\end{tabular}

From Table 4, $\beta=0.766, \mathrm{t}(\mathrm{c})=12.282, \mathrm{p}=0.000$, the equation, with adoption intention as dependent variable, the coefficient $\mathrm{c}$ is significant, the mediating effect is established; $\beta=0.625, \mathrm{t}(\mathrm{a})=8.254, \mathrm{p}=0.000$, the coefficient of the test equation is significant, the independent variables significantly affect the mediating variables; $\beta=0.824, \mathrm{t}(\mathrm{b})=14.984, \mathrm{p}=0.000$, the coefficient of the equation with adoption intention as the dependent variable is significant, and the indirect effect is significant; $\beta=0.412, \mathrm{t}\left(\mathrm{c}^{\prime}\right)=7.066, \mathrm{p}=0.000$, the coefficient of test equation is significant, the effect recommended information sources on the adoption intention is still significant, so the complete intermediary effect is not tenable. Compare ab and c', all are positive, there is some intermediary effect. At the same time, with bootstrap analysis (5000 times under the $95 \%$ confidence interval), the results show that the confidence interval of the intermediary effect of perceived usefulness (LLCI $=0.5743$, ULCI $=0.7071$ ) does not contain 0 , which reflect that the perceived usefulness plays a mediating role between the recommended information sources and the adoption intention, verifying the $\mathrm{H} 2$.

\subsection{Equations Experiment Two: The Relationship between Recommended Information Sources, Cognitive Complexity and Adoption Intention}

Experiment two, on the basis of experiment one, increases the measurement of consumers' cognitive complexity, and further explores whether consumers will 
have an impact on the adoption intention under different cognitive complexities. According to the classification of the recommended information sources, experiment two set up two scenarios such as the "recommendation based on personal preference" and "recommendation based on the relevant customers". The second is also in the class, the actual number of questionnaires is 125 , the recovery number is 114 copies. After the questionnaire statistics, according to the principle of the invalid questionnaire (regular answer, no online purchase experience, miss above three questions), eliminating 5 questionnaires, we got $112 \mathrm{fi}$ nal effective questionnaires, including $56.8 \%$ of male, $43.2 \%$ of female, the average age was 20.7 years, and the average access time for Internet (including mobile) was 3.4 hours.

As shown in Table 5 and Table 6, there is a significant difference in adoption intention between individual preference, associated customers and No referral information ( $\mathrm{M}$ personal preference $=3.709, \mathrm{SD}=0.525$ vs. $\mathrm{M}$ associated customers $=4.035, \mathrm{SD}=0.654, \mathrm{~F}=8.427, \mathrm{df}=111, \mathrm{p}=0.004)$. Therefore, H1, H1A and $\mathrm{H} 1 \mathrm{~B}$ have been verified again, that is, the recommended information sources have a significant positive effect on consumers' adoption intention, and the recommendation information based on the associated customer has higher adoption intention than recommended information based on personal preference.

Table 4. The mediating effect test of perceived usefulness.

\begin{tabular}{cccccc}
\hline & $\mathrm{t}$ & standardized regression coefficient $\beta$ & $\mathrm{SE}$ & $\Delta \mathrm{R} 2$ & Significant \\
\hline $\mathrm{c}$ & 12.282 & 0.766 & 0.055 & 0.583 & 0.000 \\
$\mathrm{a}$ & 8.254 & 0.625 & 0.059 & 0.385 & 0.000 \\
$\mathrm{~b}$ & 14.984 & 0.824 & 0.062 & 0.676 & 0.000 \\
$\mathrm{c}^{\prime}$ & 7.066 & 0.412 & 0.051 & & \\
\hline
\end{tabular}

Table 5. Mean comparison of main effects.

\begin{tabular}{ccccccc}
\hline & $\mathrm{N}$ & Mean & $\begin{array}{c}\text { Std. } \\
\text { Deviation }\end{array}$ & $\begin{array}{c}\text { Std. } \\
\text { Error }\end{array}$ & \multicolumn{2}{c}{ 95\% Confidence Interval for Mean } \\
\cline { 6 - 7 } & & & & & Lower Bound & Upper Bound \\
\hline $\begin{array}{c}\text { Individual } \\
\text { preference } \\
\text { Relevant }\end{array}$ & 55 & 3.709 & 0.525 & 0.071 & 3.567 & 3.851 \\
$\begin{array}{c}\text { customers } \\
\text { Total }\end{array}$ & 57 & 4.035 & 0.654 & 0.087 & 3.862 & 4.209 \\
\hline
\end{tabular}

Table 6. One-way ANOVA.

\begin{tabular}{cccccc}
\hline & sum of squares & df & Mean Square & F & Significant \\
\hline Between groups & 2.975 & 1 & 2.975 & 8.427 & 0.004 \\
Within groups & 38.831 & 110 & 0.353 & & \\
Total & 41.806 & 111 & & & \\
\hline
\end{tabular}


From Table 7, the mediating effect is established $(\beta=0.525, \mathrm{t}(\mathrm{c})=6.462, \mathrm{p}=$ 0.000 ); The independent variable has significant influence on the mediator variable $(\beta=0.279, \mathrm{t}(\mathrm{a})=3.047, \mathrm{p}=0.000)$. At the same time, with bootstrap analysis $(5,000$ times under the $95 \%$ confidence interval), the results show that the confidence interval of the intermediary effect of perceived usefulness (LLCI = 0.4712 , ULCI $=0.7623$ ) does not contain 0 , which reflect that the perceived usefulness plays a mediating role between the recommended information sources and the adoption intention, verifying the $\mathrm{H} 2$ again.

As shown in Table 8, the main effect of the recommended information sources on the adoption intention is not significant $(\mathrm{F}=0.467, \mathrm{P}=0.497>0.05)$, the main effect of cognitive complexity is not significant $(\mathrm{F}=0.096, \mathrm{P}=0.757>$ 0.05), but the interaction between cognitive complexity and recommended information sources is statistically significant $(\mathrm{F}=13.449, \mathrm{P}=0.001<0.05)$, so consumers' intention to adopt information come from different sources (based on individual preference, based on the relevant customers) is different, which depends on the cognitive complexity (high vs. low).

In Table 9, the results of simple effect show that when consumers' cognitive complexity is high, the average value of adoption intention of recommended information based on individual preference is 4.000 , which is significantly higher than the recommended information based on relevant customers (3.400), and

Table 7. The mediating effect test of perceived usefulness.

\begin{tabular}{cccccc}
\hline & $\mathrm{t}$ & standardized regression coefficient $\beta$ & $\mathrm{SE}$ & $\Delta \mathrm{R} 2$ & Significant \\
\hline $\mathrm{c}$ & 6.462 & 0.525 & 0.080 & 0.269 & 0.000 \\
$\mathrm{a}$ & 3.047 & 0.279 & 0.064 & 0.069 & 0.000 \\
$\mathrm{~b}$ & 10.200 & 0.697 & 0.097 & 0.481 & 0.000 \\
$\mathrm{c}^{\prime}$ & 5.704 & 0.358 & 0.062 & &
\end{tabular}

Table 8. The test of inter-subjectivity effect. Dependent variable: Adoption intention.

\begin{tabular}{cccccc}
\hline Source & $\begin{array}{c}\text { Type III Sum of } \\
\text { squares }\end{array}$ & df & Mean square & F & Significant \\
\hline Modified model & $6.771 \mathrm{a}$ & 3 & 2.257 & 4.636 & 0.006 \\
Intercept & 862.209 & 1 & 862.209 & 1771.196 & 0.000 \\
$\begin{array}{c}\text { Recommended information } \\
\text { sources }\end{array}$ & 0.227 & 1 & 0.227 & 0.467 & 0.497 \\
$\begin{array}{c}\text { Cognitive complexity } \\
\text { Recommended information } \\
\text { sources * Cognitive } \\
\text { complexity } \\
\text { Error }\end{array}$ & 0.047 & 1 & 0.047 & 0.096 & 0.757 \\
total & 6.547 & 1 & 6.547 & 13.449 & 0.001 \\
Total correction & 27.747 & 57 & 0.487 & & \\
\end{tabular}

a. $\mathrm{R} 2=0.196$ (Adjustment $\mathrm{R} 2=0.154$ 
Table 9. Simple effect of recommended information sources * cognitive complexity.

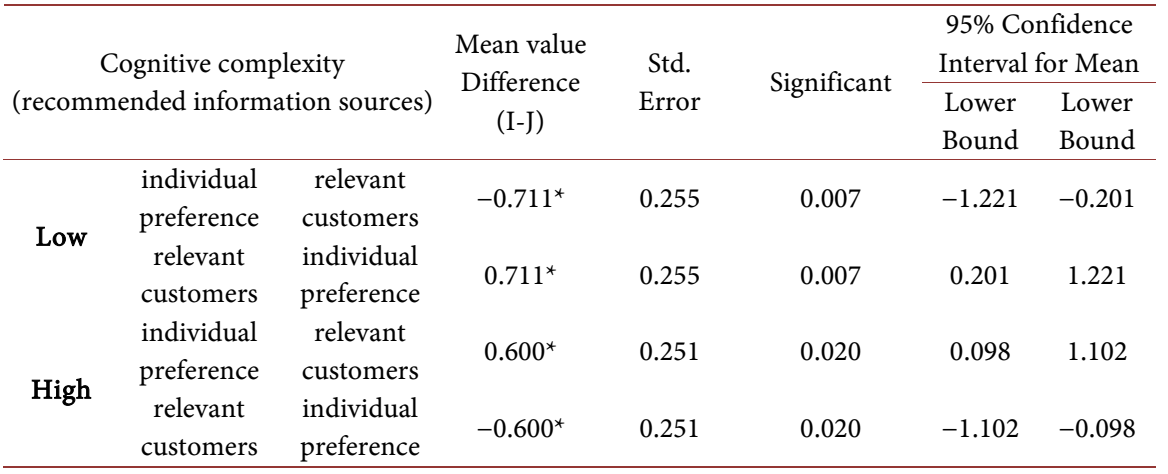

Based on estimated marginal mean *. The significant level of mean difference is 0.05 . b. Adjust multiple comparisons: Sidak.

the statistically significant $(\mathrm{F}=7.588, \mathrm{P}=0.020<0.05)$. While when consumers' cognitive complexity is low, the consumer's perceived adoption intention of associated customer is 4.178 , which is significantly higher than the average value of the individual preference (3.467), and the statistically significant $(\mathrm{F}=7.787, \mathrm{P}=$ $0.007<0.05)$. The result of simple effect is the same as the hypothesis in this paper, as is shown in Figure 2, the different cognitive complexity shown by individuals will have an impact on the information adoption intention of different information sources in the online purchase decision.

When the cognitive complexity of individual is higher, they tend to adopt recommended products based on personal preference, while the cognitive complexity of individual is lower, it is more likely for them to adopt products that are recommended by the relevant customers whose preference is similar to theirs.

\section{Conclusion and Future Research}

\subsection{Conclusion}

This study focuses on the impact of the recommended information sources on the individual adoption intention, and which kind of recommended information sources (individual preferences vs. relevant customers) are more likely to be accepted by consumers. The results show that consumers are more likely to accept recommended information comes from individuals who have similar preferences, but also differ in individual cognitive complexity. The specific manifestation is that when the individual is high cognitive complexity, the recommendation information based on personal preference is more likely to be adopted by individuals. While compared with the recommendation based on personal preference, individuals with low cognitive complexity prefer to adopt the relevant customer's recommended information. From the edge clue of recommended information sources to the individual acceptance intention, the intermediate is transmitted through perceived usefulness, which is from the perspective of information adoption. 
Estimate marginal average of individual's adoption intention

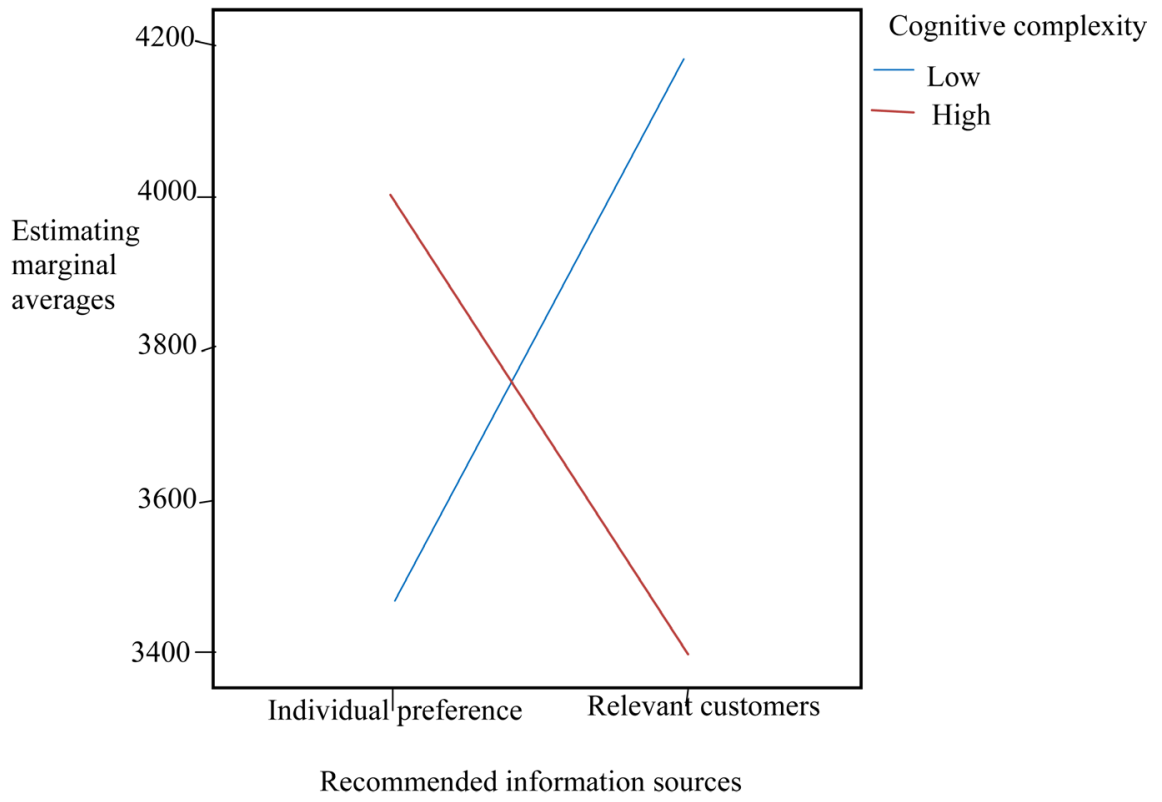

Figure 2. The interactive effect of the recommended information sources and cognitive complexity.

\subsection{Innovation of Thesis}

The current research on the recommended information sources focuses on discussing the effect of the availability of recommendations on consumer purchase decisions, satisfaction and trust, while the classification of recommended information sources focused on the recommendations of experts and other consumers' recommendations, the research in the field of personalized recommendation system is less. This research puts much more importance on the application of the recommendation system, distinguishing the recommended information sources according to the internal principles of information technology, and focuses on the difference between recommendation of individual preference and recommendation of relevant customers, enriching the research of the recommended information sources and providing reference for the relevant research in the future.

\subsection{Limitations and Future Research}

\subsubsection{Limitations}

Due to the limitations of the level, time and financial resources, this study has the following deficiencies:

On the one hand, there are some limitations in experimental methods. For the choice of experimental products, this article is directly intercepting pictures of E-commerce site, not really follow the recommended algorithm to recommend products, and for each subjects recommended products are the same, not real personalized. If the simulation laboratory can be established, the reliability of the experimental results will be improved. 
On the other hand, this paper only studies the impact of the recommended information sources on consumers' adoption intention, and does not directly study consumers' purchasing decision-making behaviors, and the factors that affect the decision-making are complex and not fully considered.

\subsubsection{Future Research}

First of all, this paper does not classify the recommended products, although two groups of experiments used different experimental products as research, but it did not include the product type as a variable into the model. Thus this can be a future research direction.

Secondly, for the study of edge clues, this article only discusses the recommendation information sources, the credibility of information sources and the impact of the Web site have not taken into account. But personalized recommendation must rely on a certain platform, so the platform itself cannot be ignored;

Finally, the angle of this article is the information adoption model, only to explore the consumer's perception of the recommended information, and then produce adoption intention, not to explore the internal formation mechanism from psychological aspect, so in the future we can start to study in this respect.

\section{References}

[1] Senecal, S. and Nantel, J. (2004) The Influence of On-Line Product Recommendations on Consumers' On-Line Choices. Journal of Retailing, 80, 159-169. https://doi.org/10.1016/j.jretai.2004.04.001

[2] Goodman, J.K., Broniarczyk, S.M., Griffin, J.G. and McAlister, L. (2013) Help or Hinder? When Recommendation Signage Expands Consideration Sets and Heightens Decision Difficulty. Journal of Consumer Psychology, 23, 165-174.

[3] Cheung, C.M.K., Lee, M.K.O. and Rabjohn, N. (2008) The Impact of Electronic Word-of-Mouth: The Adoption of Online Opinions in Online Customer Communities. Internet Research, 18, 229-247. https://doi.org/10.1108/10662240810883290

[4] Song, X.Y. and Wang, P. (2010) Research on Concept and Effective Factors of Information Adoption Behavior. Information Science, No. 5, 760-762.

[5] Gilly, M.C., Graham, J.L. and Wolfinbarger, M.F. (1998) A Dyadic Study of Interpersonal Information Search. Journal of the Academy of Marketing Science, 26, 83-100. https://doi.org/10.1177/0092070398262001

[6] Faraji-Rad, A., Samuelsen, B. and Wallop, L. (2015) On the Persuasiveness of Similar Others: The Role of Mentalizing and the Feeling of Certainty. Journal of Consumer Research, 42, 458-471. https://doi.org/10.1093/jcr/ucv032

[7] Jiang, X.P. (2011) Study on the Core Factors Impacting Search Engine Marketing. Journal of Management Sciences in China, 9, 1526-1530.

[8] Sinha, R. and Swearingen, K. (2001) Comparing Recommendations Made by Online Systems and Friends. Proceedings of the DELOS-NSF Workshop on Personalization and Recommender Systems in Digital Libraries.

[9] Estebanmillat, I., Martínezlópez, F.J., Cabal, C.C. and Gengler, C. (2015) Psychological Factors Explaining Consumer Adoption of an E-Vendor's Recommender. Industrial Management \& Data Systems, 115, 284-310. 
https://doi.org/10.1108/IMDS-10-2014-0306

[10] Yang, Y.W., Wang, Y. and Sun, G.H. (2016) Research on the Marketing Effect of Recommender System on Consumers-An Technology Acceptance Model Perspective. China Business and Market, 30, 98-107.

[11] Suedfeld, P. (1992) Motivation and Personality: Handbook of Thematic Content Analysis. Conceptual/Integrative Complexity, 393-400.

[12] Novis-Deutsch, N. (2015) Identity Conflicts and Value Pluralism-What Can We Learn from Religious Psychoanalytic Therapists? Journal for the Theory of Social Behaviour, 45, 484-505. https://doi.org/10.1111/jtsb.12079

[13] Seggelen-Damen, I.C.M.V. (2013) Reflective Personality: Identifying Cognitive Style and Cognitive Complexity. Current Psychology, 32, 82-99. https://doi.org/10.1007/s12144-013-9166-5

[14] Bu, N. and Du, X.F. (2015) The Effect of Social Cognitive Complexity on Advice Taking: The Mediating Role of Interpersonal Trust. Chinese Journal of Applied Psychology, 21, 378-384. 